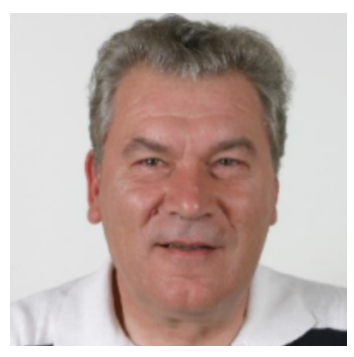

\title{
Professor Etienne Vansant, 1945-2020 A Belgian scientist who changed the complex world of Nanomaterials
}

Emeritus Professor Etienne Frans Vansant, internationally renowned Chemist, passed away on 9 July 2020. Professor A. Ch. Mitropoulos, Dean of School of Science at International Hellenic University, and his latest PhD student D.A. Gkika offer this tribute.

Etienne was born in Olen, Belgium on 20 April 1945. He obtained his bachelor's degree in Chemical Engineering in 1968 and then his PhD in Physical and Inorganic Chemistry in 1971 at the University of Leuven.

Etienne was a man of tremendous energy. A distinguished scholar and engaging Professor, was a member of the University of Antwerp community for more than four decades. He was a Professor in Inorganic Chemistry, and an authority in Adsorption and Catalysis. His contribution to nanomaterial science was so profound that he was a candidate for a Nobel Prize. Most important, he made a significant contribution to the lives of the countless students he supervised. Etienne was deeply respected by all and he was equally admired for his amazing sense of humour, modesty and kindness, as he was for his intelligence, academic mind and endless curiosity.

Over the past decades, he served as a member of multiple committees, and held consulting posts in companies, government, and educational organizations worldwide. For his research work he received many national and international awards and was rewarded for his research activities from learned societies around the world

- 1989 Medal King Leopold

- 1994 Prix VOM Prijs - Chemisorption of coupling agents on silica.

- 1996 International Ackerman Award - Characterisation of modification of silica.

- 1999 e Prix Protection de l'Environnement. L'élimination de l'huile par adsorption UGINE Min. Environnement, France

- 2005 Doctor Honoris Causa, Al. I. Cuza University of Iasi (Romania) for innovative research in nanoporous materials

Since 2012 Etienne joined Hephaestus Laboratory of the International Hellenic University in the Kavala Campus, Greece as a visiting Professor and Director of Advanced Materials. In 2016 he supervised 15 young scientists who gained a $€ 1.000 .000$ research fellowship from 
Stavros Niarchos Foundation in an attempt to intercept brain drain from Greece due to economical crisis.

Etienne enjoyed his family life and was supported throughout his career by his loving wife Monique. He is survived by one daughter and three sons. He will be remembered as a great chemist and wonderful person. To honor him, we will devote the lecture theater of our new Chemistry Department to his name. From all his friends in Kavala, we will miss him greatly. 